\title{
Erratum to: ENSO influence on the North Atlantic European climate: a non-linear and non-stationary approach
}

\author{
Jorge López-Parages ${ }^{1} \cdot$ Belén Rodríguez-Fonseca $^{1} \cdot$ Dietmar Dommenget $^{2}$. \\ Claudia Frauen ${ }^{3}$
}

Published online: 8 April 2016

(C) Springer-Verlag Berlin Heidelberg 2016

\section{Erratum to: Clim Dyn \\ DOI 10.1007/s00382-015-2951-0}

In the original publication of the article the institutional affiliations of Dr. Dietmar Dommenget and Dr. Claudia Frauen were incorrect. The correct affiliations of these coauthors are given in this erratum.

The online version of the original article can be found under doi:10.1007/s00382-015-2951-0.

Jorge López-Parages

jlopezpa@ucm.es

1 Departamento de Física de la Tierra, Astronomía y Astrofísica I (Geofísica y Meteorología). Instituto de

Geociencias UCM-CSIC, Facultad de C.C. Físicas,

Universidad Complutense de Madrid (UCM), Pza de las

Ciencias, 28040 Madrid, Spain

2 School of Mathematical Sciences, Monash University,

Clayton, VIC, Australia

3 CNRM-GAME (Météo-France/CNRS), Toulouse, France 